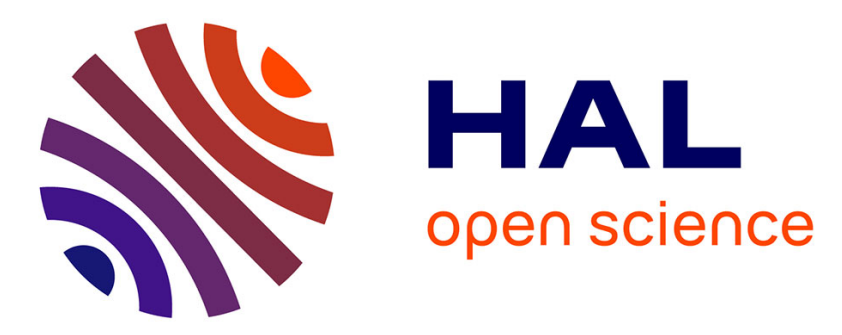

\title{
Mass Spectrometric Study of Collision Interactions of Fast Charged Particles with Water and NaCl Solutions
}

M. Kaneda, M. Shimizu, T. Hayakawa, A. Nishimura, Y. Iriki, H. Tsuchida, M. Imai, H. Shibata, A. Itoh

\section{- To cite this version:}

M. Kaneda, M. Shimizu, T. Hayakawa, A. Nishimura, Y. Iriki, et al.. Mass Spectrometric Study of Collision Interactions of Fast Charged Particles with Water and $\mathrm{NaCl}$ Solutions. The Seventh International Symposium on Swift Heavy Ions in Matter, Jun 2008, Lyon, France. hal-00281830

\section{HAL Id: hal-00281830 \\ https://hal.science/hal-00281830}

Submitted on 25 Jul 2008

HAL is a multi-disciplinary open access archive for the deposit and dissemination of scientific research documents, whether they are published or not. The documents may come from teaching and research institutions in France or abroad, or from public or private research centers.
L'archive ouverte pluridisciplinaire HAL, est destinée au dépôt et à la diffusion de documents scientifiques de niveau recherche, publiés ou non, émanant des établissements d'enseignement et de recherche français ou étrangers, des laboratoires publics ou privés. 


\title{
Mass Spectrometric Study of Collision Interactions of Fast Charged Particles with Water and NaCl Solutions
}

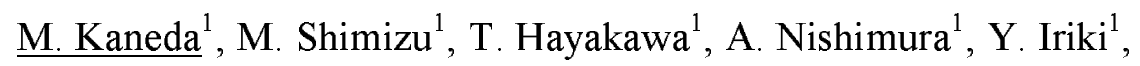 \\ H. Tsuchida ${ }^{2}$, M. Imai ${ }^{1}$, H. Shibata ${ }^{1}$, A. Itoh ${ }^{1,2}$ \\ ${ }^{1}$ Department of Nuclear Engineering, Kyoto University, Kyoto 606-8501, Japan \\ ${ }^{2}$ Quantum Science and Engineering Center, Kyoto University, Uji 611-0011, Japan
}

\begin{abstract}
A new experimental technique has been developed for the investigation of secondary particle emission from liquid targets resulting from collision interactions with fast charged particles. Secondary ion mass spectra are presented for the first time for liquid water and $0.1 \mathrm{M}, 1 \mathrm{M}$, and $5 \mathrm{M} \mathrm{NaCl}$ aqueous solutions bombarded by $2.0 \mathrm{MeV} \mathrm{He}^{+}$ions. The mass spectra exhibit a series of negative cluster ions of the form of $X_{m} Y_{n} R^{-}$, where $\mathrm{X}$ and $\mathrm{Y}$ stand for neutral molecules such as $\mathrm{H}_{2} \mathrm{O}, \mathrm{NaCl}$ and $\mathrm{NaOH}$, and $\mathrm{R}^{-}$stands for a negative charged ion such as $\mathrm{O}^{-}, \mathrm{OH}^{-}$and $\mathrm{Cl}^{-}$. Intensities of negative ions are found to change significantly as a function of the concentration. The results imply evidently that the cluster structure in liquid targets changes drastically depending on the abundance of $\mathrm{NaCl}$ in solutions.
\end{abstract}

\section{PACS: $82.80 . \mathrm{Rt}$}

Keywords: Sputtering, Liquid water, clusters, Secondary ion mass spectrometry

Corresponding author: Minoru Kaneda $<\mathrm{m}-\mathrm{k} @$,nucleng.kyoto-u.ac.jp $>$

Department of Nuclear Engineering, Faculty of Engineering, Kyoto University, Yoshida Honmachi, Sakyo-ku, Kyoto, 606-8501, Japan

Phone: +81-75-753-5821, Fax: +81-75-753-5821 


\section{Introduction}

Interaction of ionizing radiations with water is a subject receiving an increasing attention in various fields such as astronomy, atmospheric science, life science, biology, and charged particle cancer therapy [1-5]. Particularly, the charged particle cancer therapy is recognized as a powerful tool owing to the so-called Bragg peak effect, resulting in a sharp dose distribution in a particular depth of tumors. In fact, a growing number of particle therapy facilities are available worldwide

As liquid water is the major component of a human body, investigation of collision interactions of fast charged particles with liquid water and aqueous solutions is of great importance to achieve accurate understanding of physical, radiochemical and biological reactions. To date, however, experimental researches using liquid water are limited to studies of stopping range and water radiolysis, and measurements, like this work, of secondary particles have not yet been done. This is mainly due to the experimental difficulty of achieving a sufficiently good vacuum condition. Although it is obvious that secondary particles such as electrons and ions are supposed to play important roles in various biological reactions, e.g. single- and double- strand breaks, almost no investigations have been made so far. In order to achieve a breakthrough in this research field, we developed a new experimental method to measure secondary particles emitted from various liquid targets. In this work, we report for the first time experimental results of mass distributions of secondary ions emitted from liquid water and $\mathrm{NaCl}$ aqueous solution targets bombarded by $2.0 \mathrm{MeV} \mathrm{He}{ }^{+}$ions. 


\section{Experimental}

The experiment was carried out at QSEC (Quantum Science and Engineering Center) heavy ion accelerator facility of Kyoto University. Figure 1 shows a schematic drawing of our collision chamber, which consists of a liquid jet target source, a liquid-nitrogen cold trap and a time-of-flight (TOF) secondary ion mass spectrometry system.

Liquid jet targets were produced by essentially the same method as described in [6-9] The liquid jet target was prepared by injection of liquid water and $0.1 \mathrm{M}, 1.0 \mathrm{M}$, and 5.0M $\mathrm{NaCl}$ aqueous solutions through a $20 \mu \mathrm{m}$ super-fine nozzle (MUSASHI Engineering, Inc.) into the center of a collision chamber. Taking account of the liquid jet stability and vacuum condition in the collision chamber, the flow rate was kept 0.5 $\mathrm{ml} / \mathrm{min}$. The collision chamber was evacuated by a $1200 \mathrm{l} / \mathrm{sec}$ diffusion pump. In addition, the liquid jet was trapped by a liquid nitrogen cold trap at a position of about $6.0 \mathrm{~cm}$ downstream from the injection nozzle to keep a good vacuum condition. An ambient pressure during injection of liquid jets was kept below $1.0 \times 10^{-4}$ Torr.

The liquid target was crossed perpendicularly with a pulsed beam of $2.0 \mathrm{MeV} \mathrm{He}^{+}$ions at a position $1 \mathrm{~mm}$ downstream from the injection nozzle in the collision chamber. Secondary negative ions ejected from the liquid target were extracted by an electric field of $1.5 \mathrm{kV} / \mathrm{cm}$ into the flight tube of the TOF spectrometer installed perpendicularly to the incident beam by applying a static electric field. The repeller electrode $(-0.5 \mathrm{kV})$ and flight tube $(+1.0 \mathrm{kV})$ were separated by $1.0 \mathrm{~cm}$. After passing through a free flight region of $545 \mathrm{~mm}$ in length, secondary ions were detected by a pair of microchannel plates (MCPs) located at the end of the flight tube. A front voltage of the MCP was +5.0 $\mathrm{kV}$. In order to remove undesired background ions originating from evaporated gas and to keep a good vacuum condition in the flight tube, we placed an aperture of $1 \mathrm{~mm}$ in 
diameter at the entrance of the flight tube. The overall mass resolution $(\mathrm{m} / \Delta \mathrm{m})$ was about 40 .

The MCP detection efficiency of secondary ions is nearly constant of 1 in relative for the mass region below 200 as studied in this work. We note that the detection efficiency deviates considerably from 1 for large cluster ions with mass of several hundred daltons $[10]$.

3. Results and discussions

3.1. Secondary ions ejected from liquid water targets

A typical mass spectrum of negatively charged ions ejected from a jet target of liquid water is shown in Fig. 2. One can see a large peak of $\mathrm{H}^{-}$ions and a series of $\mathrm{H}_{2} \mathrm{O}$ cluster ions at positions with a mass/charge interval of 18 . These cluster ions are assigned as $\left(\mathrm{H}_{2} \mathrm{O}\right)_{\mathrm{n}} \mathrm{O}^{-},\left(\mathrm{H}_{2} \mathrm{O}\right)_{\mathrm{n}} \mathrm{OH}^{-},\left(\mathrm{H}_{2} \mathrm{O}\right)_{\mathrm{n}} \mathrm{O}_{2}^{-}$, and $\left(\mathrm{H}_{2} \mathrm{O}\right)_{\mathrm{n}} \mathrm{O}_{2} \mathrm{H}^{-}$with $n \geq 0$, where $\left(\mathrm{H}_{2} \mathrm{O}\right)_{\mathrm{n}} \mathrm{OH}^{-}$is the most abundant ion among these four types of cluster ions. The shape of these peaks is found to be considerably asymmetric and broadened, indicating that they are composed of several peaks.

These features are quite similar to those obtained for frozen water targets bombarded by $\mathrm{MeV}$ energy charged particles $[11,12]$. By contrast, in keV energy impacts, only small size cluster ions such as $\mathrm{H}\left(\mathrm{HO}_{2}\right)^{-}$and $\mathrm{H}_{2}\left(\mathrm{HO}_{2}\right)^{-}$are produced and no larger cluster ions are detected $[13,14]$. These experimental findings obtained in $\mathrm{MeV}$ and $\mathrm{keV}$ energy collisions indicate evidently that secondary electrons produced in collisions play the dominant role in the formation of negative cluster ions. This is because a large amount of electrons are produced in MeV energy collisions $[15,16]$ and such high 
degree of ionization does not occur in $\mathrm{keV}$ energy collisions.

It is known that secondary electrons with energies up to a few tens of $\mathrm{eV}$ are produced predominantly in collisions between a fast charged particle and a gas-phase water molecule $[17,18]$. Knapp et al. investigated electron attachment to cold $\mathrm{D}_{2} \mathrm{O}$ clusters produced by adiabatic expansion [19] and obtained the following results. (1) For incident electron energies between 5 and $10 \mathrm{eV}$, the main products are $\left(\mathrm{D}_{2} \mathrm{O}\right)_{\mathrm{n}} \mathrm{OD}^{-}$, $\left(\mathrm{D}_{2} \mathrm{O}\right)_{\mathrm{n}} \mathrm{O}^{-}$ions being produced only weakly, (2) at incident energies below $5 \mathrm{eV}$, very few cluster anions were produced, and (3) below $1 \mathrm{eV}$, cluster anions of $\left(\mathrm{D}_{2} \mathrm{O}\right)_{\mathrm{n}}{ }^{-}$ $(n \geq 12)$ are produced. These results are fairly suggestive to explain the present results. Namely, negatively charged ions of a series of $\left(\mathrm{H}_{2} \mathrm{O}\right)_{n} \mathrm{OH}^{-}$and $\left(\mathrm{H}_{2} \mathrm{O}\right)_{n} \mathrm{O}^{-}$are thought to be produced by capture of secondary electrons of $5 \sim 10 \mathrm{eV}$. Also, absence of $\left(\mathrm{H}_{2} \mathrm{O}\right)_{\mathrm{n}}{ }^{-}(n \leq 11)$ may be attributed to the instability of these cluster ions. It is noted that $\left(\mathrm{H}_{2} \mathrm{O}\right)_{\mathrm{n}}{ }^{-}(n \geq 12)$ ions formed by capture of $\sim 0 \mathrm{eV}$ electrons cannot be distinguished from $\left(\mathrm{H}_{2} \mathrm{O}\right)_{n} \mathrm{OH}^{-}$ions within the present mass resolution.

Figure 3 shows relative intensities of negatively charged ions $\left(\mathrm{H}_{2} \mathrm{O}\right)_{n} \mathrm{OH}^{-}$from a liquid water target as a function of the cluster size $n$. The intensity variation is found to decrease monotonously and to be fitted fairly well by $\exp (-0.19 n) \quad(\mathrm{n} \geq 3)$. It should be noted that there is no indication of the presence of magic number cluster ion, which is supposed to be formed as a result of unimolecular decomposition of an excited large cluster ion [14]. The present result implies that, in our experimental condition, even large cluster ions such as $\left(\mathrm{H}_{2} \mathrm{O}\right)_{20} \mathrm{OH}^{-}$are fully accelerated within $1 \mu \mathrm{sec}$, which is probably too short to form magic number cluster ions.

Experimental results obtained for frozen targets bombarded by energetic charged 
particles $[11,12]$ are also shown in Fig.3. An overall behavior of these cluster size distributions can be well expressed by the exponential function, $\exp (-0.12 n)$. Da Silveira et al. discussed two emission regimes of cluster ions in $[12,20]$ using frozen targets bombarded by ${ }^{252} \mathrm{Cf}$ fission fragments and by $530-850 \mathrm{keV} \mathrm{N}^{+}$ions. They called the first one "recombination regime" and the second one "fragmentation regime". The recombination regime occurs when a high temperature track core "infratrack" is formed. In this case, the temperature is sufficiently high to sublimate all the molecules in this region, resulting in a steeper decrease of cluster ion yields [20]. On the other hand, the fragmentation regime occurs in a colder region "ultratrack" formed outside an infratrack. This regime is not very destructive and the cluster distribution reflects strongly the bulk structure [20]. In the present experiment, the fragmentation regime seems to be valid, since in our condition the energy deposition per unit length $(16 \mathrm{eV} / \mathrm{A})$ is on the same order as those of $530-850 \mathrm{keV} \mathrm{N}^{+}$impacts $(35 \sim 47 \mathrm{eV} / \mathrm{A})$ and is much lower than that of ${ }^{252} \mathrm{Cf}$ fission fragments and $1.5 \mathrm{MeV} / \mathrm{u} \mathrm{Ar}^{18+}$ ions [21]. Therefore the present result also reflects strongly the bulk structure of the liquid targets. It is interesting to point out that the difference of slopes between our liquid data and other frozen ice data is certainly attributed to the phase effect of water targets.

The asymmetric peak profile of TOF spectra, exhibiting a tail toward longer flight times, is possibly the key to understand the cluster emission mechanism. The tailing peak profile is probably due to a metastable decomposition of secondary cluster ions. In case of mass $35,\left(\mathrm{H}_{2} \mathrm{O}\right) \mathrm{OH}^{-}$, the peak shape can be reproduced fairy well theoretically by taking account of a water molecule evaporation from $\left(\mathrm{H}_{2} \mathrm{O}\right)_{2} \mathrm{OH}^{-}$with a decay constant of about $4 \times 10^{6} \mathrm{~s}^{-1}$. The analysis of these decomposition reactions and 
resulting mass distributions is expected to be useful approach to investigate the energetics, liquid structures, physical and chemical reactions in the ion tracks.

\subsection{Secondary ions ejected from $\mathrm{NaCl}$ aqueous solution targets}

Figure 4 shows secondary ion mass spectra obtained for $1.0 \mathrm{M}$ and $5.0 \mathrm{M} \mathrm{NaCl}$ aqueous solutions. As for the $0.1 \mathrm{M}$ solution, being equivalent to physiological saline, the mass spectrum was almost the same as Fig. 2 measured for pure liquid water. Note that $\left(\mathrm{H}_{2} \mathrm{O}\right) \mathrm{OH}^{-}$and $\mathrm{Cl}^{-}$have the same mass of 35 .

From Fig 4 one can see clearly a drastic change of mass distributions as the concentration of $\mathrm{NaCl}$ increases. As for the $1.0 \mathrm{M}$ solution, cluster ions of mass $18 \mathrm{n}+17$, which are the sum of $\left(\mathrm{H}_{2} \mathrm{O}\right)_{n} \mathrm{OH}^{-}$and $\left(\mathrm{H}_{2} \mathrm{O}\right)_{\mathrm{n}-1} \mathrm{Cl}^{-}$, appear as the most intense peak at $n=3$. Furthermore, the intensity ratio of mass $18 n+21$ (Na contained) to $18 n+17$ (Na not contained) becomes gradually larger as the cluster size $n$ increases for $n \geq 3$. For $5.0 \mathrm{M}$, the situation changes completely. The yields of mass $18 \mathrm{n}+17$ decrease rapidly with increasing $\mathrm{n}$, and $(\mathrm{NaCl}) \mathrm{Cl}^{-}$with mass 93 is the most intense peak besides $\mathrm{OH}^{-}$and $\mathrm{O}^{-}$. At larger masses, intense peaks are positioned with a mass interval of 58, which is the $\mathrm{Na}-\mathrm{Cl}$ ion-pair.

These features are explained qualitatively as below. At low concentrations like $0.1 \mathrm{M}$, the relative abundance of solute-solvent interactions is so small that solute-containing clusters can not be detected and only water clusters are measurable in our experimental condition. With increasing concentration, the relative abundance of solute-solvent interactions becomes sufficiently high enough to detect easily solute ion containing water clusters. Also, a hydrogen bonded water network is disturbed by the solute-solvent interactions and a part of clusters is fractured to small clusters. At higher 
concentrations, where the amount of solute ions and water molecules are comparable (about 1 to 5 for $5.0 \mathrm{M}$ ), solute-solute interactions become much stronger to form clusters containing $\mathrm{Na}-\mathrm{Cl}$ ion-pairs. Moreover, water hydrogen bonds are almost broken by strong solute-water interactions. This picture also shows quantitatively a good agreement with the pair correlation functions of $\mathrm{NaCl}$ aqueous solutions [22].

In summary, a new experimental technique has been developed to measure secondary ions from liquid water and aqueous solution targets. We found that the secondary ion emission is affected strongly by not only collision interactions of primary and secondary particles with liquid targets but also various structures in liquid targets such as hydrogen bond network, solute-solvent and solute-solute interactions. The present experimental technique serves as a powerful tool both to investigate collision interactions between fast ions and liquid targets and to analyze the liquid structure at the molecular level.

\section{Acknowledgement}

This research was supported by JSPS Fellows for Young Scientists $17-02161$ and by a JSPS Grant-in-Aid for Scientific Research (B) 19360427. 
References

[1] C.S. Enos, A.R. Lee, A.G. Brenton, Int. J. Mass Spectrom. Ion Processes 104 (1991) 137.

[2] D.H. Katayama, R.E. Huffman, C.L. O’Bryan, J. Chem. Phys. 59 (1973) 4309.

[3] K. Mitsuke, T. Takami, K. Ohno, J. Chem. Phys. 91 (1989) 1618.

[4] G.H. Olivera, C. Caraby, P. Jardin, A. Cassimi, L. Adoui, B. Gervais, Phys. Med. Biol. 43 (1998) 2347.

[5] M. Dingfelder, M. Inokuti, H.G. Paretzke, Radiat. Phys. Chem. 59 (2000) 255.

[6] M. Faubel, S. Schlemmer, J.P. Toennies, Z. Phys. D 10 (1988) 269.

[7] F. Mafuné, Y. Takeda, T. Nagata, T. Kondow, Chem. Phys. Lett. 199 (1992) 615.

[8] A. Itoh, M. Kaneda, S. Satoh, K. Ishii, H. Tsuchida, Nucl. Instr. and Meth. B 245 (2006) 76 .

[9] M Kaneda, S. Sato, M. Shimizu, Z. He, K. Ishii, H. Tsuchida, A. Itoh, Nucl. Instr. and Meth. B 256 (2007) 97.

[10] A. Itoh, H. Tsuchida, T. Majima, N. Imanishi, Phys. Rev. A 59 (1999) 4428.

[11] T. Matsuo, T. Tonuma, H. Kumagai, H. Shibata, H. Tawara, J. Chem. Phys. 101 (1994) 5356.

[12] V. M. Collado, L. S. Farenzena, C. R. Ponciano, E. F. da Silveria, K. Wien, Surf. Sci. 569 (2004) 149.

[13] G. M. Lancaster, F. Honda, Y. Fukuda, J. W. Rabelais, J. Am. Chem. Soc. 101 (1979) 1951.

[14] J. W. Chirstiansen, I. S. Tsong, J. Chem. Phys. 86 (1987) 4701.

[15] L. H. Toburen, W. E. Wilson, R. J. Popowich, Radiat. Res. 82 (1980) 27.

[16] G. Willems, W. Y. Baek, B. Grosswendt, Radiat. Pro. Dosi. 99 (2002) 347. 
[17] D. Ohsawa, H. Kawauchi, M. Hirabayashi, Y. Okada, T. Honma, A. Higashi, S. Amano, Y. Hashimoto, F. Soga, Y. Sato, Phys. Rev. B 227 (2005) 431.

[18] C. Champion, O. Boudrioua, C. Dal Cappello, Y. Sato, D. Ohsawa, Phys. Rev. A 75 (2007) 032724.

[19] M. Knapp, O. Echt, D. Kreisle, E. Recknagel, J. Phys. Chem. 91 (1987) 2601.

[20] R. Martinez, C. R. Ponciano, L. S. Farenzena, P. Iza, M. G. P. Homem, A. Naves de Brito, K. Wien, E. F. da Silveira, Int. J. Mass Spectrom. 253 (2006) 112.

[21] J. F. Ziegler, SRIM2008, available from <http://www.srim.org $>$.

[22] S. Bouazizi, S. Nasr, N. Jaidane, M. C. B. Funel, J. Phys. Chem. B 110 (2006) 23515 . 


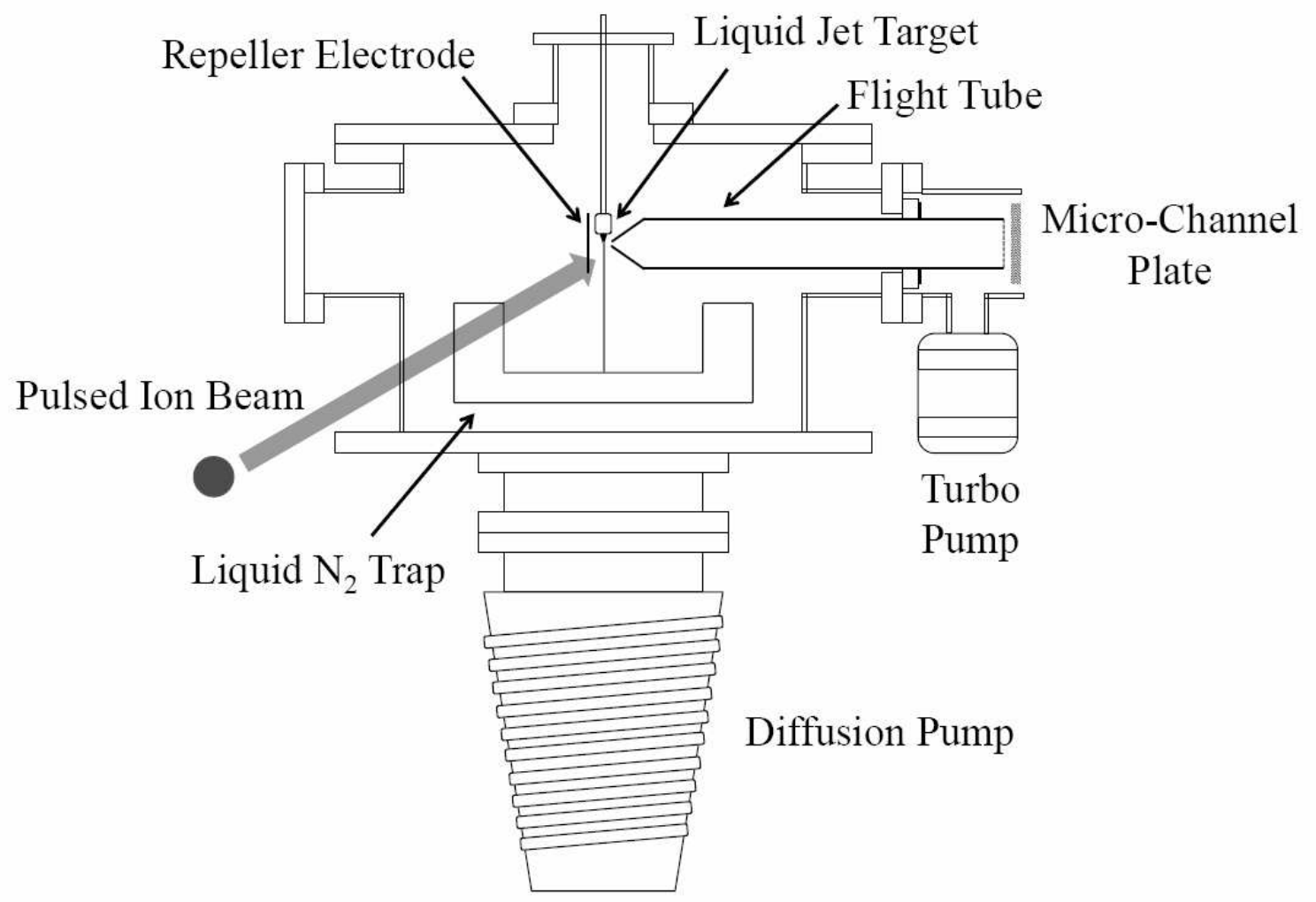

Figure.1 Schematic drawing of the present experimental setup - consists of a liquid jet target source, a liquid $\mathrm{N}_{2}$ cold trap, and a time-of-flight mass spectrometry system. The flight tube entrance has an aperture of $1.0 \mathrm{~mm}$ in diameter. 


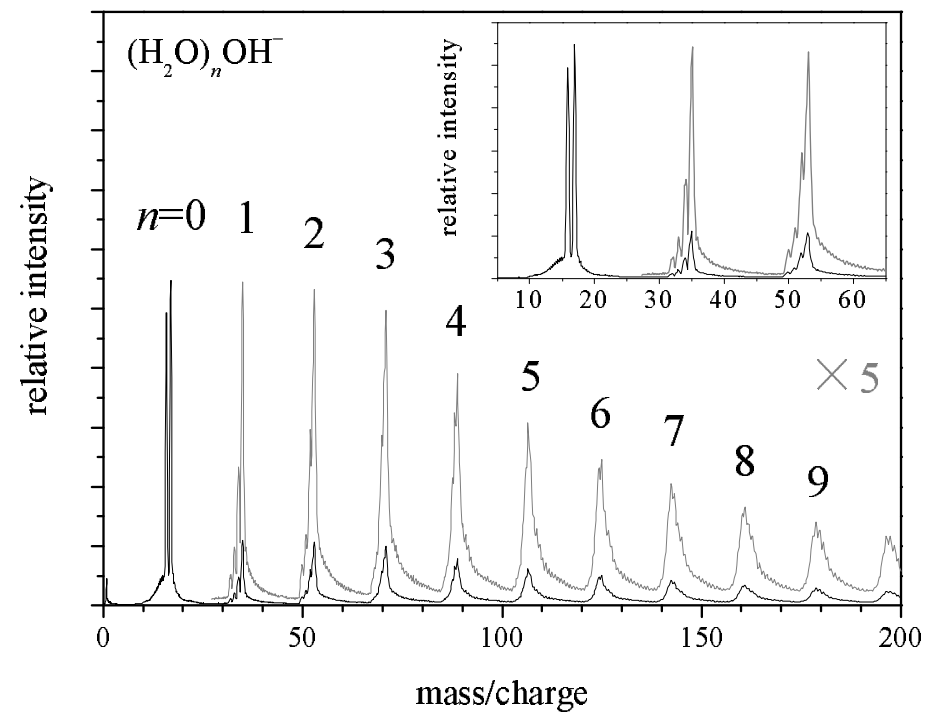

Figure 2. Negative ion spectrum from a liquid water target, showing a series of intense cluster ions consist of dominant peaks of $\left(\mathrm{H}_{2} \mathrm{O}\right)_{n} \mathrm{OH}^{-}$and weaker signals of $\left(\mathrm{H}_{2} \mathrm{O}\right)_{n} \mathrm{O}^{-}$, $\left(\mathrm{H}_{2} \mathrm{O}\right)_{n-1} \mathrm{HO}_{2}^{-}$and $\left(\mathrm{H}_{2} \mathrm{O}\right)_{n-1} \mathrm{O}_{2}^{-}$(see an inner figure).

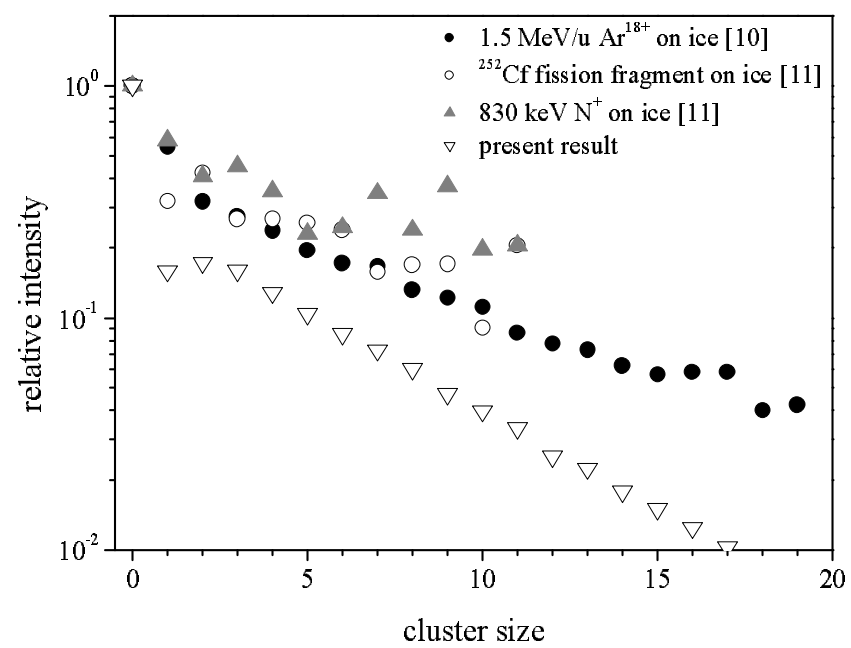

Figure 3. Cluster size distributions of $\left(\mathrm{H}_{2} \mathrm{O}\right)_{n} \mathrm{OH}^{-}$obtained for liquid (present) and frozen water targets $[10,11]$. 


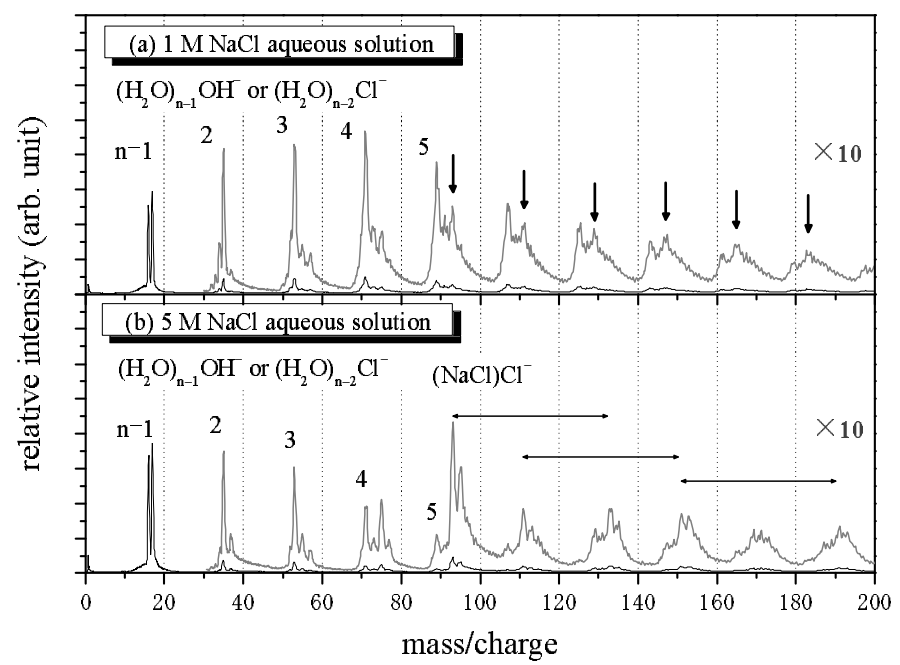

Figure 4. Negative ion spectra from two NaCl aqueous solutions of (a) $1 \mathrm{M}$ and (b) $5 \mathrm{M}$. Downward arrows in (a) represent Na containing clusters and two-headed arrows in (b) show mass/charge intervals of 58 ( $\mathrm{Na}$-Cl ion pair). 